\section{Health sector reforms in the Region of the Americas}

\author{
The Editorial Committee
}

This special issue of the Revista Panamericana de Salud Pública/Pan American Journal of Public Health offers readers an up-to-date analysis of the recent past and of the present of health sector reforms in the Region of the Americas, as well as a vision of their future.

This journal issue is part of the efforts that the Pan American Health Organization/World Health Organization (PAHO/WHO) has been carrying out since the beginning of the 1990s to provide the countries of the Americas with the greatest amount of information, relevant experiences, policy guidelines, and useful instruments for designing and implementing substantive changes in the health sector.

At the first Summit of the Americas, in 1994, PAHO/WHO received the mandate to track the progress of health sector reforms in the Region and to evaluate the results of those efforts. Along with the World Bank and the Inter-American Development Bank, in 1995 PAHO/WHO convened the Special Meeting on Health Sector Reform, and also intensified efforts to assist in this area. In $1997 \mathrm{PAHO} / \mathrm{WHO}$ disseminated a position paper on the processes of health sector reform. In that same year the U.S. Agency for International Development, PAHO/WHO, and other partners jointly launched an initiative on health sector reform in Latin America and the Caribbean. The purpose of that initiative is to support reform processes that promote equitable access to more effective health services. Over the last three years the initiative has become a valuable information source for participants in the health reform process.

This special journal issue has been organized into three main sections. The first section, which is devoted to the past and present of reforms, describes the context, status, and trends of reforms and also analyzes in depth most of the subjects that were critical to change agendas during the 1990s-and that to a large extent still are.

The second section, entitled "The future of reforms," poses questions and tries to explore the new challenges that are emerging at the beginning of the new millennium. These include the relationships between social security systems and health systems, as well as the challenges of dealing with persons excluded from health care, of strengthening the practice of public health, of reorienting health systems and services with promotion criteria, and of conceiving and harmonizing international cooperation in this field.

The third section, entitled "Toward a new generation of reforms," consists of an article that illustrates the lessons culled from the health sector reforms that have been launched since the late eighties and the critical issues that will be dealt with in the coming years.

The three sections are complemented by a series of country case studies that present experiences in one or more areas of health sector reform. These pieces were written by persons responsible for health sector policies and by professionals with extensive experience and prestige in their particular countries.

Preparing this journal issue has been a challenge that the Editorial Committee faced with strong interest and determination. We wanted to create an arena where multiple views could be presented, from such fields as politics, academia, health systems and services management, and international development. This effort forced us to read, to reflect, and to discuss more and more with each other. It showed us how complex and dynamic the subject of health reform is, and how relative the knowledge of it can be. But above all, it motivated us to continue to work in support of the health of the peoples of the Americas and of functional, sustainable health systems that serve the common good. And the effort suggested to us ideas and ways to continue trying to do that.

We hope that the readers will share our view that the result that we are offering was worth the effort. 